\title{
O LABORATÓRIO COMO ESPAÇO DA PRODUÇÃO DOS FATOS CIENTÍFICOS NO PENSAMENTO DE LATOUR E WOOLGAR VINÍCIUS CARVALHO DA SILVA ${ }^{1}$, RENATO DA SILVA VICENTINI ${ }^{2}$, HARUMI MATSUMOTO ${ }^{3}$ E BRENO SABINO LEITE DE SOUZA ${ }^{4}$
}

RESUMO: Neste artigo faremos uma apresentação crítica do "realismo ascendente" de Bruno Latour e Steve Woolgar, em Vida de Laboratório, obra em que investigam o funcionamento de um laboratório de neuroendocrinologia buscando compreender como os fatos científicos são socialmente construídos. Assumindo uma postura radical, descartam a ontologia realista mais comum, rompem com a epistemologia da filosofia da ciência tradicional, com a história e a sociologia da ciência e mesmo com a antropologia. Concluem que o laboratório - primeiro aquele específico, estudado, e depois em sentido geral - é um espaço de produção literária técnica onde os fatos científicos são construídos. A concepção de ciência dos autores levanta problemas filosóficos tradicionais, além de requerer uma formalização lógica.

PALAVRAS-CHAVE: Laboratório, pesquisa científica, ciência e tecnologia, enunciados científicos, fatos científicos.

ABSTRACT: In this paper we will present a critical presentation of Bruno Latour and Steve Woolgar's "ascending realism" in Laboratory Life, in which they investigate the functioning of a neuroendocrinology laboratory in order to understand how scientific facts are socially constructed. Assuming a radical stance, they discard the most common realist ontology, break with the epistemology of traditional science philosophy, with the history and sociology of science, and even with anthropology. They conclude that the laboratory - first that specific, studied, and then in a general sense - is a space of technical literary production where the scientific facts are constructed. The authors' conception of science raises traditional philosophical problems, besides requiring a logical formalization.

KEYWORDS: Laboratory, scientific research, science and technology, scientific statements, scientific facts.

\footnotetext{
${ }^{1}$ Professor na Universidade Estadual do Tocantins (UNITINS), professor convidado na disciplina de Filosofia da Ciência na pós-graduação em Biofísica do Instituto de Biofísica Carlos Chagas Filho da Universidade Federal do Rio de Janeiro (UFRJ) e professor colaborador do Mestrado Profissional em Filosofia na Universidade Federal do Tocantins (UFT). Doutor em Filosofia da Ciência e Teoria do Conhecimento pela Universidade do Estado do Rio de Janeiro (UERJ). E-mail: viniciusfilo@gmail.com.

${ }^{2}$ Mestre em História das Ciências e da Saúde pela COC-Fiocruz (Fundação Oswaldo Cruz/Casa Oswaldo Cruz). E-mail: vicentinirenato@gmail.com.

${ }^{3}$ Docente nos cursos de Medicina e Enfermagem no UNIFESO (Centro Universitário Serra dos Órgãos). Mestre em História das Ciências e da Saúde pela COC-Fiocruz (Fundação Oswaldo Cruz/Casa Oswaldo Cruz). E-mail: harumienf@hotmail.com.

${ }^{4}$ Doutorando em História das Ciências e da saúde pela COC-Fiocruz (Fundação Oswaldo Cruz/Casa Oswaldo Cruz). E-mail: breno.sabino@hotmail.com.
} 
Em Vida de Laboratório Bruno Latour e Steve Woolgar narram algo inusitado para ouvidos incautos: o laboratório é um scriptorium, um lugar para ler e escrever cujo principal objetivo é a criação de ordem - o ordenamento da natureza. Todavia, dito de tal modo, não se percebe o quão radical é tal proposta. Quando falamos em "ordenamento da natureza", pressupomos dois tipos de realismo. No primeiro caso temos um real preexistente, cujos dados são ordenados a partir de um determinado evento. No segundo, uma realidade ordenada preexistente. No segundo caso, portanto, "ordem" e "realidade" são indissociáveis e preexistentes. No entanto, para Latour e Woolgar, o realismo não é imanente ou "descendente", mas "ascendente". Partimos de algo que está aí, mas que ainda não é a natureza - enquanto conjunto dos fatos naturais - e o elevamos do nível da incerteza pura ao nível de fato natural.

O que fazemos no laboratório é construir, passo a passo, a natureza, ordenando-a por meio de um complexo encadeamento de procedimentos científicos que tem a produção literária como objetivo. Tal produção demanda o desenvolvimento e a utilização de máquinas, instrumentos, de um "complexo tecnológico". Por isso podemos considerar que, no pensamento dos autores, no laboratório se dá a "produção tecno-lógica da natureza". A tecnologia nos permite produzir enunciados, sentenças lógicas que pretendem representar "fatos". Fixar algo na literatura é construir um fato natural. Todavia, a questão fulcral é justamente a de assumir que antes da ordenação não podemos falar em realidade ou natureza. Ordenar é criar. O laboratório, ao gerar uma literatura que instaura uma ordem do mundo, dá o primeiro passo no sentido da criação dos fatos naturais. Evidentemente, e não sem razão, o realismo científico, apelando ao princípio de razão suficiente nos dirá que nada é criado do nada, e que se o laboratório produziu a construção tecno-lógica ${ }^{5}$ dos fatos, é por que partiu do pressuposto ontológico da possibilidade de ordenação do real. Em nossa visão Latour e Woolgar não enfrentam essa questão, e a concepção de ciência que propõem sugere um problema, mas deixao de lado. O que o laboratório faz é ordenar a realidade ou elaborar um sistema de enunciados cuja ordem aparente apenas busca representar uma ordem subjacente ${ }^{6}$

Os pesquisadores de um laboratório passam seu tempo efetuando operações sobre enunciados: acréscimos de modalidades, citações, aprimoramentos, subtrações, empréstimos, proposições de novas combinações. Deste modo, pesquisadores de laboratório podem ser retratados como escritores e leitores "compulsivos" que trabalham com uma "rede de textos".

\footnotetext{
${ }^{5}$ No presente artigo utilizamos o termo "tecno-lógica" para abarcar a complexa relação entre "tecnologia" e "lógica" nas práticas científicas de laboratório. A tecnologia está presente em todos os processos e possui um papel de força criadora na construção dos enunciados científicos. Os enunciados, por sua vez, são sentenças lógicas, que afirmam ou negam determinados predicados para sujeitos específicos.

${ }^{6}$ Nesta ocasião não pretendemos explorar essa dificuldade do trabalho de Latour e Woolgar.
} 
Estes escritores são autores de enunciados e têm por finalidade criar enunciados capazes de ascender em uma escala de faticidade que vai da especulação pura à naturalização dos enunciados em fatos, e à reificação dos fatos em objetos. O próprio laboratório está composto por objetos técnicos, dentre os quais muitos inscritores. A maquinaria de um laboratório também é a materialização de uma literatura e representa o resultado de uma história de estratégias, debates e controvérsias. O pesquisador de laboratório é como um demônio de Maxwell que aumenta a entropia global para criação de ordem local. Do caos material do "movimento browniano" de materiais, informações, artigos e inscrições à construção dos fatos ordenados a ordem é construída à custa do aumento da entropia do laboratório:

O que separa o cientista do caos é uma parede de arquivos, de etiquetas, de livros de protocolos, de números e de artigos. Mas essa massa de documentos fornece o único meio de criar mais ordem e, assim - tal como o demônio de Maxwell -, de aumentar a quantidade de informação em algum lugar (LATOUR; WOOLGAR. 1997, p.281).

É o que se passa no laboratório. Uma desordem imensa é gerada (manipulação de matéria, dados, inscrições, enunciados de baixa facticidade) para que algum quantum de ordem seja extraído. Ao final se fabrica a natureza em sua unidade e harmonia, não como ponto de partida, mas como produto final. Para ela apontamos garbosos e dizemos: Vê, é o real! Não somente uma etnografia, mas essa inovadora e provocadora ontologia, na qual a ordem da natureza não é a priori, dá-nos o Lab life de Latour e Woolgar.

\section{Vida de Laboratório}

Vida de Laboratório de Bruno Latour e Steve Woolgar é o resultado de dois anos de pesquisa de campo de Latour no Laboratório de Neuroendocrinologia do Instituto Salk, na Califórnia, entre os anos de 1975 e 1977. O grupo de cientistas que Latour acompanhou era chefiado por Roger Guillemin, endocrinologista francês, laureado com Nobel de Medicina em 1977 - dividido com o cientista polonês Andrew Schally - pela descoberta da estrutura química do Hormônio (ou Fator) TRH (ou TRF) produzido no hipotálamo. Foi este importante cientista quem convidou Latour, seu compatriota, para pesquisar no renomado laboratório norte americano, abrindo-lhe as portas e dando-lhe livre acesso às correspondências, aos rascunhos, às reuniões e à rotina de trabalho do local. A parceria com o sociólogo inglês Steve Woolgar ocorreu posteriormente, quando sua pesquisa já estava concluída. Woolgar terminava sua tese de doutorado, sendo um apaixonado por etnometodologia e o problema da reflexividade, atributos que conduziram Latour a convidá-lo para redigir com ele sua etnografia do laboratório (LATOUR; WOOLGAR. 1997). 
Antes de iniciar este trabalho, ainda no início da década de 1970, Latour esteve na Costa do Marfim com uma equipe de antropólogos que se esforçavam para explicar, por um viés cultural, por qual razão era tão difícil os trabalhadores africanos se adaptarem às relações modernas de trabalho. O objetivo era, através do discurso científico da antropologia, diminuir o peso dos discursos concorrentes que imputavam aos negros uma capacidade cognitiva menor. O rigor científico da equipe de antropólogos era grande. Foi a partir daí que surgiu uma curiosidade no autor,

O que dizer do discurso científico se ele fosse estudado com o cuidado que os etnógrafos têm quando estudam as culturas, as sociedades e os discursos pré, para ou extracientíficos? A 'dimensão cognitiva' não estaria, aí também, amplamente exagerada? (LATOUR; WOOLGAR. 1997, p. 12-13).

Foi com este objetivo (de utilizar as ferramentas da etnometodologia para estudar os cientistas como se fossem uma tribo exótica) e com esta hipótese (de que os fatores cognitivos eram supervalorizados no discurso da produção do saber científico) que Latour iniciou a sua jornada no laboratório em questão. Como o próprio autor deixa claro, uma das principais ousadias do seu trabalho é provocar a antropologia a romper com seus limites usuais que a circunscrevem ao estudo das periferias. Como ciência da periferia, a antropologia sempre se voltou para as "margens" do planeta e, posteriormente, as "margens" das grandes metrópoles do mundo, deixando intocados os centros de poder, os redutos das elites e o status quo de um modo geral. Como em nossa sociedade ocidental poucas práticas são tão sacralizadas quanto as ciências, este era um objeto de estudo perfeito como desafio intelectual.

Latour reconhece que seu objeto de estudo não é novo, todavia ele aponta a inadequação das análises tradicionais ao classificar toda a literatura anterior como "pia" (isto é, sacralizadora da ciência), "memorial" (feita por cientistas a partir de suas memórias. Por melhor que fossem essas obras, todas careciam de pesquisa, observação direta e contradição) e "licenciosa" (que expõe as fraquezas e o lado humano dos cientistas, mas preserva intocada a imagem sagrada do fato científico construída pela literatura 'pia') (LATOUR; WOOLGAR. 1997). Ainda nesta linha das abordagens inadequadas, Latour critica a Sociologia das Ciências (que explorou toda dinâmica social das instituições científicas, mas deixou intocado o núcleo cognitivo das ciências), a História das Ciências (que até criou bons vínculos entre os aspectos cognitivos e sociais das ciências do passado, mas se furtou a abordar a ciência feita no século XX) e a História Social das Ciências (que abordou a ciência do século XX, mas não foi ao campo, logo explicou muito pouco sobre o seu "núcleo rígido", isto é, cognitivo).

O objetivo de Latour, através de sua microssociologia pós-estruturalista, é dar conta daquilo que todas as abordagens anteriores, segundo ele, foram incapazes de fazer, isto é, abrir 
a "caixa-preta" das ciências, tocar diretamente no seu "núcleo rígido", ou seja, nos aspectos cognitivos da construção de conhecimentos, expondo sua dimensão social. Neste sentido, o autor - profundamente influenciado pelo arcabouço teórico de Thomas Kuhn e, sobretudo, de David Bloor - se põe como um continuador direto do Programa Forte, tendo como seus principais guias norteadores os conceitos de simetria $^{7}$ e reflexividade ${ }^{8}$. Entretanto, o autor também chama a atenção para a necessidade de se cunhar novos conceitos se o cientista social quiser avançar nos estudos sobre a ciência, pois os velhos conceitos, criados há longas datas, não dariam conta desta empreitada.

Partindo do princípio que não apenas os cientistas podem falar sobre ciência - assim como não são apenas os economistas que falam sobre economia, nem somente os políticos que falam sobre política -, Latour está convicto de que pode socializar-se na "tribo" dos cientistas e compreender a sua linguagem e os seus "ritos", como qualquer outro antropólogo o faz em qualquer outra tribo do mundo. Seu grande desafio, como o de todo antropólogo, não seria o de se ambientar, mas, ao contrário, seria o de se afastar de seu objeto após estar socializado, mantendo a distância necessária para não adotar para si a linguagem do cientista, sendo capaz de criar uma metalinguagem que dê conta de nos explicar o que é a ciência sem precisar recorrer àquilo que o cientista diz ser a ciência. Este é o princípio da etnometodologia de Latour, dar voz ao cientista, sem confiar cegamente no que ele diz sobre o seu trabalho, distinguindo, na medida do possível, aquilo que ele realmente faz daquilo que ele diz fazer (LATOUR; WOOLGAR. 1997).

$\mathrm{Na}$ seção seguinte abordaremos como o autor desenvolve, metodologicamente, suas técnicas para superar a sua ignorância inicial sobre ciência - ele também se diz um tanto quanto ignorante em língua inglesa, a língua falada por seus "nativos" - e organizar o caos mental inicial com o qual se depara para, posteriormente, cumprir a sua meta de abrir a "caixa-preta" científica.

\footnotetext{
${ }^{7}$ Segundo o qual os instrumentos metodológicos da sociologia servirão para elucidar tanto os erros quanto os acertos científicos. Este conceito é radicalizado por Latour, que afirma que a sociologia deve tratar como equivalentes não apenas os acertos e os erros científicos, mas também natureza e sociedade. (LATOUR; WOOLGAR. 1997, p. 23-24).

${ }^{8}$ Segundo o qual com os mesmos critérios que a Sociologia julga as outras ciências e suas "verdades", ela própria e seus próprios enunciados também devem ser julgados, sem qualquer privilégio. (LATOUR; WOOLGAR. 1997, p. 30).
} 


\section{A construção de um fato no laboratório}

Como o próprio autor deixa claro na questão (diversamente formulada) levantada acima, o objetivo central do seu trabalho é elucidar como uma verdade é forjada no seio de uma comunidade científica. Enquanto os epistemólogos diziam que o resultado do trabalho científico era revelar a verdade, que viria como um fruto da objetividade do método, aplicado dentro de um processo puramente cognitivo, lógico e racional, Latour, através de sua etnometodologia, tomou por principal tarefa demonstrar os processos sociais envolvidos neste processo de construção da verdade, empreendido pelos cientistas ${ }^{9}$. A questão fulcral da obra de Latour e Woolgar, então, é aquela da construção dos fatos científicos, cujo esquecimento de sua história social reforçará seu conteúdo de facticidade. Eis o problema central: como um enunciado chega a ser um fato?

Como a objetividade que não tem a sociedade por origem é produzida por essa sociedade? Para falar como Bachelard, como é feito um fato? Para falar como Serres (1987), como o objeto chega ao coletivo? Para falar como Shapin e Shaffer (1985), como a política da experiência produz uma experiência infinitamente distante de toda a política? Para dizer como Bloor, como o conteúdo emerge de seu contexto? É unicamente com relação a essa questão diversamente formulada que se deve julgar os limites desta primeira pesquisa de campo (LATOUR; WOOLGAR. 1997 p.34).

Podemos pensar a criação de fatos científicos como o processo de construção social da própria natureza. Para Latour e Woolgar, não há um fundamento ontológico objetivo a priori que ordena e unifica o real. Ordem e unidade são produzidas em laboratório à medida que dados são convertidos em enunciados, enunciados em fatos, fatos em objetos. Estranha maiêutica em que a própria natureza é trazida à luz.

A natureza ordenada é obra das práticas científicas, assim como a música é obra de compositores. Não existe música antes da composição bem como não há o que se falar acerca da natureza antes da construção dos fatos. Tal noção guarda paralelo com a concepção de Ian Hacking em Representar e Intervir:

(...) se diz que os cientistas explicam os fenômenos que descobrem na natureza [posição filosófica realista mais comum]. Mas sei que eles, muitas vezes, criam os fenômenos que acabam se tornando as peças centrais das teorias [grifo nosso] (HACKING. 2012, p. 319).

Partindo do princípio de que a ciência não é uma esfera isolada da vida social, tal prática - tal qual a política, a economia, a religião e tantas outras atividades humanas - também estaria

\footnotetext{
${ }^{9}$ Conforme Jan Golinski, uma "realidade artificial” é criada nos laboratórios. Estes, portanto, são espaços de criação e produção da realidade. O uso da noção de "artificialidade", todavia, é bastante sutil nesse caso, pois essa realidade criada é justamente aquilo que chamamos de "natureza". A natureza, deste modo, não é nosso ponto de partida, não "está lá", a priori, mas, antes disso, é o resultado, a construção resultante das práticas científicas. Ver: GOLINSKI, Jan. Making Natural Knowledge: Constructivism and the History of Science. Cambridge: Cambridge University Press, 1998. p. 31.
} 
imersa no mundo da cultura, sendo passível de uma profunda análise social, não apenas em suas esferas institucionais (ou seja, em suas bordas), mas, igualmente, em seu núcleo rígido, isto é, na sua produção de saber propriamente dita.

Utilizando a noção de cultura "como um conjunto dos valores e das crenças - que suscitam paixões, temores e respeito - a que constantemente se recorre na vida cotidiana" e compreendendo que dentro desta se formam mitologias "que no sentido antropológico seriam quadros de referências no sentido amplo, no interior dos quais se podem localizar as atividades e as práticas de uma cultura particular", Latour e Woolgar compreendem os paradigmas científicos como sendo mais uma forma de mitologia que se formou no interior da nossa cultura. Os autores empregam o conceito de paradigma como uma mistura complexa de crenças, hábitos, tradições orais e práticas, no interior da qual podemos encontrar "fundadores míticos" e "revoluções" (LATOUR WOOLGAR. 1997, p. 48-49).

Olhando as coisas por este ângulo seria possível, segundo Latour e Woolgar, visualizar os cientistas neuroendocrinologistas como uma "tribo", pois compartilham de um mesmo conjunto de crenças, isto é, de uma mitologia (ou paradigma) - que parte da crença (ou tese) de que o cérebro é quem controla as glândulas do sistema endócrino. Dentro desta "tribo" há um "subgrupo", estudado diretamente pelo autor, que compartilha um paradigma/mitologia particular, segundo o qual o controle do cérebro sobre o sistema endócrino se daria por meio dos fatores de liberação - substâncias químicas discretas, de natureza peptídica (em cadeias de aminoácidos), produzidas pelo hipotálamo. Logo, a identificação, o isolamento, a nomeação e posterior reprodução artificial destes fatores de liberação seriam o principal foco de trabalho deste "subgrupo", ocupando-os em todo o seu período de atividades.

A princípio, o grande obstáculo para Latour era descobrir um método que permitisse abordar o conteúdo social do trabalho destes cientistas. Percebeu que o objetivo final do trabalho de laboratório (cuja rotina, em grande parte, consistia em registrar e ler coisas) era a produção de artigos científicos, que circulassem intensamente no interior de uma rede de especialistas, da qual o seu laboratório era apenas um ponto. Não tardou para que Latour identificasse aquele grupo como uma "tribo de leitores e autores de artigos". Foi neste contexto que tomou como ferramenta o conceito de inscrição literária para abordar, como literatura, o conteúdo dos dados que circulavam no interior dos artigos, sem necessariamente ter que compreender o que estes informavam em termos estritamente científicos. Assim, o autor poderia utilizar uma metalinguagem própria para abordar a linguagem científica da qual não podia se tornar refém. 
Por este método, os "dados" produzidos como resultados das experiências (variados tipos de gráficos) foram tomados como inscrições produzidas por inscritores (as máquinas), que, embora relegados ao campo da "pura técnica", seriam, para Latour, a teoria científica reificada. O saber científico teria, assim, uma dívida impagável com estas máquinas, com os técnicos que as operam e com as indústrias que as produzem, pois são elas que produzem os "dados" que, se confirmados, vão parar nos artigos em forma de "enunciados científicos". Um aspecto interessante observado pelo autor é que estes "dados", assim que confirmados, são abordados como exteriores a estas máquinas, ou seja, produtos da natureza apreendidos pelo intelecto, enquanto as máquinas e seus técnicos seriam logo esquecidos.

\section{Tipos de fato e níveis de faticidade.}

As inscrições, produzidas pelos inscritores, seriam então a matéria-prima dos enunciados científicos que circulam nos artigos. Estes enunciados podem variar bastante em seus níveis de facticidade, dependendo da presença ou não de modalidades (ponderações e citações que reforçam o enunciado) que os acompanham. Latour cria uma escala entre os diferentes níveis de enunciados, esta escala vai de 1 a 6: sendo 1 o enunciado com modalidades que o põe no nível das conjecturas e especulações; no nível 2 teríamos enunciados com modalidades que indicam hipóteses ainda carentes de comprovação; no 3 teríamos afirmações cautelosas, isto é, com algum nível de incerteza; no 4 teríamos enunciados expressos, livres de qualquer modalidade, isto é, um fato científico propriamente dito, digno dos manuais; no 5 estariam os enunciados que dispensariam qualquer tipo de explicação complementar, de tão assimilados que foram; e no nível 6 teríamos formulações naturalizadas, que não seriam mais enunciadas, nem refletidas, sendo apenas operadas como ferramentas ou conhecimento tácito, como "fatos", dados básicos da realidade ${ }^{10}$.

\footnotetext{
${ }^{10}$ A classificação dos tipos de enunciados feita por Oliveira pode ser útil:
}

Tipo 1 - o enunciado está situado na esfera da especulação e das conjecturas, sendo influenciado por muitas variáveis modalizadoras;

Tipo 2 - declarações ou afirmações que contêm modalidades que podem ser consideradas como de descrédito (destrutivas) do enunciado, típico de controvérsias que se dão no início de discussões sobre determinado conceito;

Tipo 3 - reivindica-se nessa categoria certa naturalização do fato, embora com modalidades que podem ser compreendidas como acrescentando argumentos, assertivas (construtivas) que vão criando realidade ao enunciado original, mas também modalidades negativas como no tipo 2; 
Antes de se tornar um fato científico, o enunciado científico circularia, através dos artigos, no interior da rede científica acompanhado por uma série de estratégias discursivas que jogariam com estas modalidades, aumentando e/ou diminuindo o seu nível de facticidade. Conseguir um enunciado de tipo 5 - como descrever a fórmula química e indicar a função de um fator de liberação $\operatorname{TRF}(\mathrm{H})$, por exemplo - seria o ponto máximo de qualquer laboratório científico. Depois de estabelecido, o fato institui a realidade que enuncia e se desprende de toda a rede discursiva da qual emergiu, apagando sua trajetória de controvérsias e incertezas. Este campo de forças que faz flutuar o valor de um enunciado é o que Latour chama de campo agonístico.

Desta forma, Latour pretende nos mostrar que a ciência é uma prática social como qualquer outra, ou seja, trata-se de uma prática de produção de enunciados através de técnicas persuasivas dentro de um sistema de convenções socialmente estabelecido. Este jogo de convencimento não é regido unicamente pela razão ou pela rigidez do método científico, pois tanto os enunciados fundamentados em dados corretos (fatos) quanto os enunciados fundamentados em dados errados (artefatos) teriam a mesma origem, logo, outros fatores (ligados a poder, prestígio, financiamentos etc.) estariam imbricados neste complexo jogo político. Mostrar in loco como este processo acontece, dando exemplos concretos - como no caso do cientista Roger Guillemin, que utilizou todo o seu prestígio e poder econômico para reformular os paradigmas do seu campo de estudos, eliminando, através disso, muitos dos seus concorrentes de pesquisa - pode ser um dos grandes méritos deste livro.

Como um dos desdobramentos da análise de Bruno Latour sobre a prática científica como inscrição literária e a sua ideia de que a ciência é uma apuração de enunciados, decorre o questionamento sobre a possibilidade de um observador compreender a construção social de um fato tomando-o em seu estado consolidado. Ou seja, após o apagamento que compõe a

Tipo 4 - as modalidades nessa etapa vão sendo superadas por comprovações, e a facticidade do enunciado tomase plausível, mantendo-se ainda um vínculo de necessidade de identificar, por exemplo, o autor do enunciado;

Tipo 5 - representam assertivas que mais se aproximam dos fatos, em que já não se adicionam modalidades nem destrutivas nem construtivas e raramente se faz menção aos autores. Deste ponto em diante o conhecimento torna-se tácito e normalmente é incorporado às novas situações de uso científico ou popular.

Ver: OLIVEIRA, Moisés Alves. Estudos de Laboratório no Ensino Médio a partir de Bruno Latour. Educação e Realidade.31 (1) 163-182, jan/jun 2006.

Oliveira omite o sexto nível, talvez por que nele já não temos enunciados, e sim "fatos". Os enunciados, no sexto nível, foram completamente naturalizados e assimilados, no uso comum, como entidades naturais objetivas, cujo problema da existência já não se coloca. 
própria constituição de um fato de todos os fatores sociais que estiveram envolvidos no processo. Para tanto, o autor opta por analisar o caso do TRF(H), que se tornou um fato no ano 1969 a partir da publicação de oito artigos que tiveram o papel de, após anos de pesquisas e diversas interferências, torná-lo um fato estabelecido no sentido latouriano.

$\mathrm{O}$ caminho proposto por Latour para ter acesso àquilo que foi apagado no processo de estabelecimento do fato foi recuar ao momento em que as balizas dessa subdisciplina foram demarcadas, em 1962. Naquele ano, as pesquisas realizadas para a busca do hormônio foram reestruturadas por um laboratório que detinha autoridade suficiente para reestabelecer critérios na área - anteriormente pesquisas eram feitas em direção ao hormônio, mas em bases distintas das que seriam definidas a partir de então. A redefinição das pesquisas em 1962 foi responsável por definir naquele momento o que deveria ser buscado, como deveria ser buscado e o que poderia ser achado, uma vez que os critérios de validação da facticidade também foram remodelados.

Desta forma, Latour trabalhou com um período muito bem delimitado assim como com um grupo muito específico. Pensando nas ciências como práticas em rede, acredita que a facticidade de um objeto é relativa à sua posição nesta rede, pois, em uma rede mais ampla em torno do $\operatorname{TRF}(\mathrm{H})$ ele é apenas uma ferramenta aplicada a outros objetos. No entanto, dentro de um grupo muito específico e durante o período em que as bases da subdisciplina são definidas até a sua construção como fato, o $\operatorname{TRF}(\mathrm{H})$ possui uma dimensão muito diferente para os 20 indivíduos que dedicam suas vidas profissionais para determinar a estrutura química deste elemento.

Quando se permanece no âmbito da análise das publicações ou citações para descrever a evolução de um domínio, há alguns inconvenientes. Pode-se concluir que os limites de uma área são objetivamente independentes daqueles que dela participam. Para evitar que isso ocorra em sua análise, Latour procura mostrar que o desenvolvimento desta área poderia ter outro caminho. Estratégias, disputas, soluções criativas, controle do cientista sobre o laboratório são elementos centrais para a compreensão do fazer científico ora proposto. Latour volta-se para uma microssociologia dos fatos no laboratório, observando as conversas que os cientistas têm entre si. Assim, podemos parafrasear Geertz ao considerar a etnografia da prática científica como um estudo no laboratório e não do laboratório. (KROFT, 1989).

Latour percebe que os cientistas do laboratório discutem o que pode ser aceito e o que não em meio a uma variedade de formas de conversas e assuntos. A dimensão humana nessa microssociologia do laboratório é, segundo o autor, uma faceta mais explícita que em outros 
espaços na ciência. Na verdade, o autor de um enunciado conta tanto quando o próprio enunciado. O maior desafio neste estudo é estender essa forma de análise para a dimensão do pensamento.

$\mathrm{O}$ argumento de Latour assume que se aceitarmos o discurso científico sobre a ciência como correspondente a uma narrativa de acordo com a qual a ciência é um produto exclusivamente racional, cognitivo, fruto do pensamento puro, não haverá espaço para análises sociológicas, já que a própria condição de estabelecimento de um fato é o apagamento da dimensão social. Assim, é necessário entender esse efeito discursivo para podermos desmontar a lógica do pensamento cientifico e mostrá-lo dotado daquilo que ele se esforçou em eliminar. Apenas dessa forma o pensamento científico pode ser compreendido sociologicamente. Portanto, a ciência é social não apenas em sua prática cotidiana, mas inclusive e necessariamente na sua forma de pensamento.

\section{Níveis de enunciados e transformações de enunciados}

Optamos por representar simbolicamente as relações entre enunciados e níveis de facticidade ${ }^{11}$.

$$
\begin{aligned}
& \downarrow \mathrm{E}_{6}=\mathrm{F}_{3} \rightarrow \mathrm{c}_{1+} \mathrm{m}_{0+} \mathrm{p}_{0+} \mathrm{a}_{0} \\
& \downarrow \uparrow \mathrm{E}_{5}=\mathrm{F}_{2.2} \rightarrow \mathrm{c}_{1+} \mathrm{m}_{0+} \mathrm{p}_{0+} \mathrm{a}_{1} \\
& \downarrow \uparrow \mathrm{E}_{4}=\mathrm{F}_{2.1} \rightarrow \mathrm{c}_{1+} \mathrm{m}_{0+} \mathrm{p}_{1+} \mathrm{a}_{1} \\
& \downarrow \uparrow \mathrm{E}_{3}=\mathrm{F}_{2} \rightarrow \mathrm{c}_{1+} \mathrm{m}_{1^{2}} \mathrm{p}_{1+} \mathrm{a}_{1} \\
& \downarrow \uparrow \mathrm{E}_{2}=\mathrm{F}_{1} \rightarrow \mathrm{c}_{<1+} \mathrm{m}_{1^{1}+} \mathrm{p}_{1+} \mathrm{a}_{1} \\
& \uparrow \mathrm{E}_{1}=\mathrm{F}_{0} \rightarrow \mathrm{c}_{0+} \mathrm{m}_{1+} \mathrm{p}_{1+} \mathrm{a}_{1}
\end{aligned}
$$

\footnotetext{
${ }^{11}$ Hierarquia dos enunciados em um realismo ascendente: Na representação acima temos os seis tipos de enunciados distribuídos em 3 níveis de facticidade:

$\mathrm{E}_{1} \mathrm{~F}_{0}=$ Certeza negativa $\left(\mathrm{c}_{0}\right)$, Modalidade positiva $\left(\mathrm{m}_{1}\right)$, Publicidade positiva $\left(\mathrm{p}_{1}\right)$, Agonística positiva $\left(\mathrm{a}_{1}\right)$ $\mathrm{E}_{2} \mathrm{~F}_{1}=\mathrm{C}$. indeterminada $\left(\mathrm{c}_{<1}\right)$, Modalidade positiva $1\left(\mathrm{~m}_{1}^{1}\right)$, Publicidade positiva $\left(\mathrm{p}_{1}\right)$, Agonística positiva $\left(\mathrm{a}_{1}\right)$

$\mathrm{E}_{3} \mathrm{~F}_{2}=$ Certeza positiva $\left(\mathrm{c}_{1}\right)$, Modalidade positiva $2\left(\mathrm{~m}_{1}^{2}\right)$, Publicidade positiva $\left(\mathrm{p}_{1}\right)$, Agonística positiva $\left(\mathrm{a}_{1}\right)$

$\mathrm{E}_{4} \mathrm{~F}_{2.1}=$ Certeza positiva $\left(\mathrm{c}_{1}\right)$, Modalidade negativa $\left(\mathrm{m}_{0}\right)$, Publicidade positiva $\left(\mathrm{p}_{1}\right)$, Agonística positiva $\left(\mathrm{a}_{1}\right)$

$\mathrm{E}_{5} \mathrm{~F}_{2.2}=$ Certeza positiva $\left(\mathrm{c}_{1}\right)$, Modalidade negativa $\left(\mathrm{m}_{0}\right)$, Publicidade negativa $\left(\mathrm{p}_{0}\right)$, Agonística positiva $\left(\mathrm{a}_{1}\right)$

$\mathrm{E}_{6} \mathrm{~F}_{3}=$ Certeza positiva $\left(\mathrm{c}_{1}\right)$, Modalidade negativa $\left(\mathrm{m}_{0}\right)$, Publicidade negativa $\left(\mathrm{p}_{0}\right)$, Agonística negativa $\left(\mathrm{a}_{0}\right)$
} 
Para compreender os tipos de enunciados e seus níveis de facticidade é importante apresentarmos alguns conceitos básicos. No escopo do presente estudo, assumimos que os enunciados têm um grau de certeza. Quando são completamente especulativos, conjecturais, sem nenhuma justificativa empírica, dizemos que sua possibilidade de certeza é "negativa" $\left(\mathrm{c}_{0}\right)$. A partir do momento em que o enunciado possua algum amparo empírico diremos que seu conteúdo de possibilidade de certeza é positivo $\left(\mathrm{c}_{1}\right)$. Os enunciados que se tornam "fatos" ou dados brutos da realidade, que foram naturalizados, perdendo sua história, autoria, elevando-se para além de todo debate, tornam-se não somente "possivelmente certos", mas "realmente certos". Por exemplo, o enunciado "todos os corpos pesados caem" expressa uma crença de senso comum totalmente naturalizada, representando, portanto, um "fato". Logo, no senso comum, que o assimilou, ele não é "possivelmente certo", mas "realmente e absolutamente certo", não importando sua história e autoria. Não classificamos diversos graus de certeza para além dos valores binários 0 e 1 . Modalidades são asserções que podem contribuir para que um enunciado seja rejeitado (modalidades destrutivas) ou assumido (modalidades construtivas). Os enunciados são modalmente negativos $\left(\mathrm{m}_{0}\right)$ quando não possuem modalidades. Os enunciados são modalmente positivos quando possuem modalidades. Quando as modalidades são apenas destrutivas dizemos que são $\mathrm{m}_{1}{ }^{1}$, quando, além das destrutivas, há, em maior número, modalidades construtivas, dizemos que são $\mathrm{m}_{1}^{2}$. Dizemos que os enunciados possuem publicidade negativa $\left(\mathrm{p}_{0}\right)$ quando perdem a autoria e sua história. Quando dizemos que "a lua é o satélite natural da terra" tomamos o enunciado por um fato natural, um dado bruto da realidade. Esquecemos (ou "não importa") a partir de quando, e de "quem", tal enunciado tornou-se o caso. Quando ainda podemos ligar um enunciado a uma história e seus autores, então dizemos que sua publicidade é positiva $\left(\mathrm{p}^{1}\right)$. Quando um enunciado não é mais objeto de controvérsias e disputas, e não precisa mais ser expresso publicamente, dizemos que sua agonística ${ }^{12}$ é negativa $\left(\mathrm{a}^{0}\right)$; quando ainda é objeto de debates e não se encontra subentendido, sua agonística é positiva $\left(\mathrm{a}^{1}\right)$.

À medida que um enunciado possui certeza positiva (c) e que perde em modalidade (m), publicidade (p) e agonística (a), ele eleva seu nível de facticidade.

\footnotetext{
12 Aqui utilizamos o conceito de agonística no sentido apontado por Latour e Woolgar de "campo de disputas". Os enunciados competem entre si. Diferentes grupos de pesquisadores pretendem convencer a comunidade da correção dos seus enunciados. Os cientistas querem persuadir uns aos outros que seus enunciados constituem fatos. Tal disputa é, ao mesmo tempo, social, política e epistemológica.
} 
Enunciados de tipo 6 (fatos tácitos) e tipo 1 (especulações ou conjecturas) são contrários. Isso fica evidente quando notamos que a carga de seus componentes é invertida. São polos opostos no "espectro de enunciados".

$$
\begin{aligned}
& \mathrm{E}_{6}=\mathrm{F}_{3} \rightarrow \mathrm{c}_{1+} \mathrm{m}_{0+} \mathrm{P}_{0+} \mathrm{a}_{0} \\
& \mathrm{E}_{1}=\mathrm{F}_{0} \rightarrow \mathrm{c}_{0+} \mathrm{m}_{1+} \mathrm{P}_{1+} \mathrm{a}_{1}
\end{aligned}
$$

Como vimos acima, os enunciados de tipo 6 possuem o maior nível de facticidade, são positivos quanto à possibilidade de certeza (nesse caso, como são "fatos", a certeza é "absoluta") e negativos quanto à modalidade, publicidade e agonística, ao passo que os enunciados de tipo 1 são negativos em relação à possibilidade de certeza e positivos no que diz respeito aos demais parâmetros.

Os enunciados não são formas fixas, estáticas. Pelo contrário, são construções dinâmicas que podem subir ou descer de nível caso, por exemplo, percam modalidades destrutivas ou ganhem modalidades construtivas. Conforme os autores, "a destruição das modalidades, por exemplo, no enunciado de tipo 3 , resulta em um enunciado de tipo 4 , cujo grau de facticidade aumenta em proporção" (LATOUR \& WOOLGAR.1997, p. 81).

$$
\begin{aligned}
& \mathrm{E}_{4}=\mathrm{F}_{2 \cdot 1} \rightarrow \mathrm{c}_{1+} \mathrm{m}_{0+} \mathrm{p}_{1+} \mathrm{a}_{1} \\
& \mathrm{E}_{3}=\mathrm{F}_{2} \rightarrow \mathrm{c}_{1+} \mathrm{m}_{1+}{ }_{1+} \mathrm{p}_{1+} \mathrm{a}_{1}
\end{aligned}
$$

Quando promovemos uma subtração modal total em um enunciado de tipo 3 ele se transforma em um enunciado não-modal de tipo 4. Com isso, seu nível de facticidade se eleva. Notamos que o 1 que denotava a carga positiva da modalidade no enunciado de tipo 3 é zerado no enunciado de tipo 4. Consequentemente o nível de facticidade no enunciado de tipo 4 ganha 1 ponto. Diagramas (Esteticamente semelhantes aos de Feynman na física) podem ser muito úteis para representarmos os diversos tipos de interação entre enunciados. Vejamos alguns poucos exemplos de interações que podem ocorrer fazendo com que um enunciado suba ou desça de nível: 


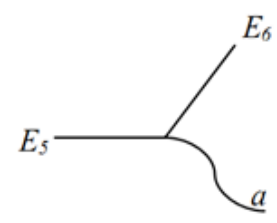

Podemos ler esse diagrama da seguinte forma: "um enunciado de Tipo 5 perde sua autoria e se transforma em um enunciado de tipo 6". Isto é, quando os enunciados de uma determinada teoria científica são completamente assimilados pela cultura geral e naturalizados, se transformam em fatos naturais, ou dados brutos da realidade. Outros dois exemplos, tirados agora dos próprios autores:

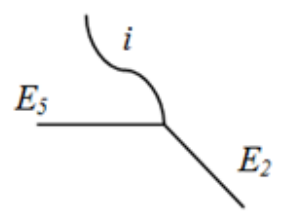

"Vale [um cientista] lança uma dúvida sobre um enunciado (...) de tipo 5. Disso resulta que um original de tipo 5 se transforma em um enunciado altamente conjectural de tipo 2 " (LATOUR WOOLGAR. 1997, p. 97).

O segundo exemplo dos autores:

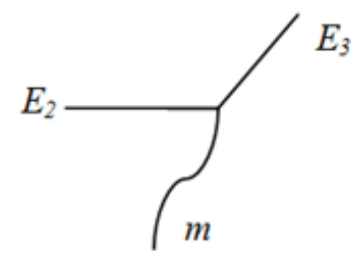

"Vale transforma um enunciado de tipo 2 em um enunciado de tipo três aumentando sua carga modal por meio do acréscimo de referências confirmatórias" (LATOUR WOOLGAR. 1997, p. 97). Lembramos que as modalidades podem ser destrutivas $\left(\mathrm{m}_{1}{ }^{1}\right) \mathrm{e}$ construtivas $\left(\mathrm{m}_{1}^{2}\right)$. Quando um enunciado se torna parte da "mitologia científica" vigente, ou do paradigma aceito, as modalidades destrutivas já foram zeradas e as construtivas se tornaram desnecessárias. 


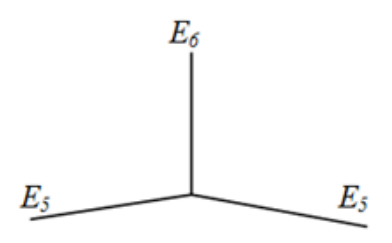

No diagrama anterior, dois enunciados de tipo 5 se reforçam ou se confirmam, e se transformam em um enunciado de tipo 6.

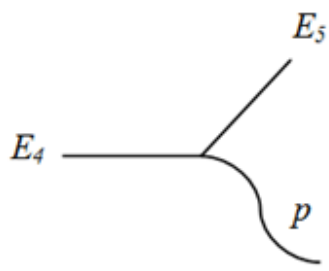

Acima, um enunciado de tipo 4 perde parte da publicidade, deixando de ter que ser publicamente referenciado a partir de sua história e autoria, e se transforma em um enunciado de tipo 5. Quando o processo total de perda da publicidade e da agonística se completar, esse enunciado de tipo 5 se transformará em um "fato", ou enunciado de tipo 6.

O objetivo final dos escritores científicos, isto é, dos cientistas de laboratório, é a produção de uma imagem unificada e ordenada da natureza. Logo, eles devem fazer com que enunciados de baixo nível (como $0,1,2,3$ ) subam a níveis mais elevados, até galgar o nível 5. Com a consolidação de uma determinada "mitologia científica", esses enunciados chegam ao nível 6. O pesquisador de laboratório é como um demônio de Maxwell que aumenta a entropia global para criação de ordem local.

O que separa o cientista do caos é uma parede de arquivos, de etiquetas, de livros de protocolos, de números e de artigos. Mas essa massa de documentos fornece o único meio de criar mais ordem e, assim - tal como o demônio de Maxwell -, de aumentar a quantidade de informação em algum lugar (LATOUR; WOOLGAR. 1997, p. 281).

No laboratório uma desordem imensa é gerada (manipulação de matéria, dados, inscrições, enunciados de baixa facticidade) para que algum quantum de ordem seja extraído. Um aspecto de fundamental importância para pesquisas ulteriores é a analogia que os autores sugerem entre as práticas científicas e as econômicas. Todo esse processo de transformação de enunciados não está despido de tensões, negociações e disputas sociais. Os cientistas "negociam" enunciados com a credibilidade de suas carreiras, institutos, projetos. Esses fatores também são "modais", ou seja, podem contribuir para a elevação ou rebaixamento de um enunciado. 


\section{Considerações finais}

Todos os argumentos de Latour apresentados desde sua entrada no laboratório e seu procedimento metodológico de adaptação à rotina do local, até nos momentos em que parece entender muito bem a disciplina que está analisando a ponto de traçar a história de um fato, confluem para um sistema que inclui cientistas, produção de conhecimento, reconhecimento, credibilidade, financiamento, reinvestimento da credibilidade. Aquilo que muitas vezes aparece de forma fragmentada durante o livro, começa a ganhar unidade na ideia de credibilidade e num sistema circular que alimenta o fazer científico, numa analogia retirada da economia. Assim, pesquisas são capazes de alimentar novas pesquisas futuras, cientistas de manter laboratórios e redefinir seus campos investindo sua credibilidade para isso. Social, literária, em rede, circular e simbólica é a ciência traçada por Bruno Latour e Steve Woolgar nesta "vida de laboratório". Tal prática opera criando desordem e gerando uma imensa e diversificada produção literária, para dela extrair alguma ordem e unidade. O "demônio de Latour-Woolgar" cria uma profusão de enunciados a galgar as escadas do real, que tem por base a especulação pura, e a natureza por cume. A concepção dos autores nos faz pensar em um "realismo ascendente", em que a "natureza" não é o fundamento, o dado de entrada, mas o resultado de um processo. O laboratório lida com um "caos" que não é a "natureza ordenada", mas uma profusão de dados, impressões, eventos, conjecturas, testes, tensões e disputas. O que chamamos de natureza emergiria somente ao final de um longo e meticuloso processo de produção de enunciados capazes de escalar os níveis mais elevados de uma "cadeia" (ou "espectro de facticidade"). Os "fatos" naturais seriam os enunciados que sobreviveram a uma rigorosa seleção ao longo desse processo. A possibilidade de ordenamento do real seria o pressuposto ontológico das práticas científicas de laboratório. O real, enfim ordenado, o resultado final.

\section{REFERÊNCIAS BIBLIOGRÁFICAS}

GOLINSKI, J. Making Natural Knowledge: Constructivism and the History of Science. Cambridge: Cambridge University Press, 1998.

HACKING, I. Representar e Intervir: tópicos introdutórios de Filosofia da Ciência Natural. Pedro Rocha de Oliveira (Trad.) Rio de Janeiro: Eduerj, 2012.

HERNÁNDEZ, A.; NAVARRO, L. Etnografias de laboratório e o programa da antropologia. Ensaios Filosóficos, Volume VIII - Dezembro/2013. Disponível em: $<$ http://www.ensaiosfilosoficos.com.br/Artigos/Artigo8/01_navarro_laura_hernandez_antonio .pdf $>$ Acesso em julho de 2016. 
KROPF, S. P.; FERREIRA, L. O. A prática da ciência: uma etnografia no laboratório. História, Ciências, Saúde - Manguinhos, 1998, vol.4, n.3, pp. 589-597.

LATOUR, B; WOOLGAR, S. A Vida de Laboratório: a produção dos fatos científicos. Rio de Janeiro, Relume Dumará. 1997.

OLIVEIRA, M. A. Estudos de Laboratório no Ensino Médio a partir de Bruno Latour. Educação e Realidade. 31 (1) 163-182, jan/jun 2006 